\title{
TRACER STUDY LULUSAN PROGRAM STUDI ILMU HUKUM UNIVERSITAS TERBUKA
}

\author{
Megafury Apriandhini, Purwaningdyah Murti Wahyuni, Dewi Mutiara, \\ Nadia Nurani Isfarin, Madiha Dzakiyyah Chairunnisa \\ Universitas Terbuka (UT) Jakarta, Indonesia \\ Email:megafury@ecampus.ut.ac.id, purwaningdyah@ecampus.ut.ac.id, \\ dewim@ecampus.ut.ac.id, nadian@ecampus.ut.ac.id, \\ madiha.chairunnisa@ecampus.ut.ac.id
}

Received: 2020-08-15; Accepted: 2020-08-05; Published: 2020-09-15

\begin{abstract}
Abstrak
Program Studi Ilmu Hukum di Universitas Terbuka memberikan peluang kepada siapapun, di manapun, dan kapanpun untuk menemempuh pendidikan tinggi sebagai sarana meningkatkan kompetensi diri dalam bidang hukum. Kurikulum dirancang dan diperbarui sesuai dengan kebutuhan mahasiswa selama studi. Untuk mengukur ketercapaian kompetensi lulusan dalam dunia kerja perlu dilakukan penelurusan melalui tracer studi. Hal ini menjadi tantangan tersendiri karena beragamnya lulusan yang tersebar di seluruh wilayah Indonesia. Dengan metode penelusuran melalui penyebaran kuesioner yang disebar melalui email, aplikasi whatsapp, dan melalui hubungan telepon dilakukan untuk mencapai sampling sebesar 25\% dari keseluruhan lulusan. Prodi IImu Hukum baru mulai meluluskan pada tahun 2017, hingga 2019 sudah tercatat terdapat 1.402 lulusan yang terjaring dalam tracer study. Berdasarkan hasil yang diperoleh dari penelitian ini, lulusan Prodi IImu Hukum bekerja pada bidang hukum dengan presentase lebih dari $90 \%$. Dari keseluruhan lulusan mendapatkan manfaat dengan gelar sarjana hukum, yaitu mendapatkan pekerjaan di bidang hukum atau mendapatkan manfaat atas gelarnya di instansi tempat dia bekerja sebelumnya
\end{abstract}

Kata Kunci: tracer study; mutu pendidikan; profil lulusan

\begin{abstract}
Law Program at the Universitas Terbuka provides opportunities for anyone, anywhere, and at any time to pursue higher education as a means of increasing self-competence in the field of law. The curriculum is designed and updated according to the needs of students during their studies. To measure the achievement of graduate competencies in the world of work, it is necessary to trace through a study tracer. This is a challenge in itself because of the variety of graduates scattered throughout Indonesia. With the search method through the distribution of questionnaires distributed via email, whatsapp application, and by telephone, it is carried out to achieve a sampling of $25 \%$ of all graduates. Law Program only started graduating in 2017, until 2019 there were 1,402 graduates who were caught in the tracer study. Based on the results obtained from this research, more than $90 \%$ graduates of the Law Study Program work in the legal field. Overall, graduates benefit from a law degree, namely getting a job in the field of law or benefiting from their degree in the institution where they previously worked.
\end{abstract}

Keywords : tracer study; education quality; graduate profile 


\section{PENDAHULUAN}

Saat ini pendidikan nasional menghadapi berbagai tantangan yang sangat berat khususnya dalam upaya menyiapkan kualitas sumber daya manusia yang mampu menghadapi persaingan global. Pembangunan sumber daya manusia yang berkualitas dan unggul turut mendukung kemajuan bangsa, terlebih dalam menghadapi era revolusi industri seperti sekarang ini, bangsa Indonesia harus menghadapi persaingan dengan kreativitas, inovasi, dan kecepatan (Baro'ah, 2020).

Pendidikan adalah segala daya upaya dan semua usaha untuk membuat masyarakat dapat mengembangkan potensi manusia agar memiliki kekuatan spiritual keagamaan, pengendalian diri, berkepribadian, memiliki kecerdasan, berakhlak mulia, serta memiliki keterampilan yang diperlukan sebagai anggota masyarakat dan warga negara. Di samping itu pendidikan merupakan usaha untuk membentuk manusia yang utuh lahir dan batin cerdas, sehat, dan berbudi pekerti luhur Mampu berperan penting dalam mencerdaskan bangsa merupakan salah satu tujuan dari perguruan tinggi sebagai pihak penyelenggara Pendidikan. Pihak perguruan tinggi tentu saja memiliki harapan dapat mencetak lulusanlulusan yang memiliki daya saing serta kompetensi yang tinggi dan berkualitas (Rini \& Tari, 2013).

Tantangan yang dihadapi oleh perguruan tinggi di Indonesia saat ini adalah terbatasnya kesempatan kerja yang dapat menyerap lulusan perguruan tinggi sehingga menyebabkan jumlah pengangguran sarjana-sarjana kian menumpuk. Belum lagi kendala yang dihadapi pihak perguruan tinggi itu sendiri yaitu kesulitan pembiayaan sehingga sulit berkembang untuk menjadi perguruan tinggi yang berkualitas (Fuadi, 2016).

Para lulusan di saat terjun langsung ke dunia kerja yang sesungguhnya mampu mengimplementasikan ilmu yang diperoleh selama duduk di bangku kuliah sehingga mereka tidak saja dapat menjadi lulusan yang siap kerja namun mampu menciptakan lapangan kerja (Nurdyansyah \& Andiek, 2017).

Untuk memperoleh gambaran secara garis besar mengenai kemampuan lulusan dalam berkiprah di dunia kerja sesuai dengan bidang ilmu Pendidikan yang diperolehnya dapat dilakukan dengan melakukan penelusuran melalui tracer studi. Tracer studi sendiri merupakan salah satu upaya dalam meningkatkan kualitas perguruan tinggi dan upaya pelaksanaan pemeringkatan bidang kemahasiswaan perguruan tinggi yang berada di lingkungan Kementerian Pendidikan dan Kebudayaan (Yahya, 2018).

Dokumen Tracer studi merupakan salah satu upaya yang diharapkan dapat menyediakan informasi untuk mengevaluasi hasil pendidikan di Politeknik Harapan Bersama dari kuisioner yang diberikan kepada alumni. Informasi kuisioner ini digunakan untuk pengembangan lebih lanjut sebagai bahan evaluasi Politeknik Harapan Bersama dalam memperbaiki kualitas pendidikan (Bakti, Noval, \& Aji, 2017).

Tracer Studi disebut pula survey alumni merupakan studi mengenai lulusan Lembaga penyelenggaraan Pendidikan tinggi. Studi ini bertujuan menyediakan berbagai informasi yang sangat bermanfaat bagi evaluasi hasil Pendidikan tinggi dan untuk ke depannya dapat dimanfaatkan untuk penyempurnaan dan penjaminan kualitas Lembaga Pendidikan Tinggi tersebut. Hasil dari tracer studi dapat menyediakan berbagai informasi penting mengenai hubungan antara Pendidikan tinggi dan dunia kerja professional, menilai relevansi Pendidikan tinggi, informasi bagi pemangku kepentingan (stakeholders) serta untuk melengkapi persyaratan bagi akreditasi pendidikan tinggi (Atmini, Budianto, \& Ahsan, 2019).

Megafury Apriandhini, et. al. / Tracer Study Lulusan Program Studi IImu Hukum Universitas Terbuka 
Pendidikan bermutu adalah pendidikan yang mampu melakukan proses pematangan kualitas siswa yang dikembangkan dengan cara membebaskan siswa dari ketidak tahuan dan ketidak mampuan

Setelah meluncurkan kebijakan Merdeka Belajar, Menteri Pendidikan dan Kebudayaan, Nadiem Makarim mengungkapkan bahwa kampus merdeka perlu menyesuaikan kebijakan di lingkup Pendidikan tinggi, salah satunya dengan mewajibkan pelaksanaan tracer studi setiap tahun.

Sebagai salah satu dari penyelenggara pendidikan, Universitas Terbuka (UT) adalah perguruan tinggi negeri yang menyelenggarakan pendidikan jarak jauh. UT memiliki Pendidikan jarak jauh dijelaskan dalam Undang-Undang Nomor 12 tahun 2012 tentang Pendidikan Tinggi sebagai proses belajar mengajar yang dilakukan secara jarak jauh melalui penggunaan berbagai media komunikasi. Seiring dengan kebutuhan industri dan kebutuhan teknologi UT terus meningkatkan layanan dan lulusan melalui sistem pendidikan tinggi terbuka dan jarak jauh (PTTJJ).

Sistem pendidikan terbuka yang diterapkan UT mengandung arti bahwa UT dalam menyelenggarakan pendidikan mengutamakan dan menekankan keterbukaan sistem yang merupakan operasionalisasi filosofi pendidikan sepanjang hayat (tanpa seleksi masuk, tanpa batasan usia, tanpa batasan lokasi geografis, tidak mempersyaratkan latar belakang multi entry- multi exit). Dengan sistem pendidikan jarak jauh UT mendorong terjadinya kemandirian belajar bagi peserta didik agar mampu mengarahkan diri sendiri dalam mengorganisasikan proses belajar dan dalam memanfaatkan layanan bantuan belajar yang disediakan oleh UT. Dengan demikian, sistem PTTJJ yang diterapkan UT menghasilkan fleksibilitas sistem dan menjamin aksesibilitas masyarakat terhadap pendidikan tinggi sesuai misi UT (bin Saper et al., 2018).

Tujuan dari penelitian tracer study adalah penelitian mengenai situasi lulusan khususnya dalam kemanfaatan pemerolehan kompetensi selama kuliah di UT. Selaras dengan melaksanakan maka visi UT menjadi perguruan tinggi terbuka dan jarak jauh (PTTJJ) berkualitas dunia. Untuk mencapai visi tersebut Program Studi (prodi) Ilmu Hukum melakukan penelusuran lulusan dengan penelitian tracer studi Prodi IImu Hukum UT (Syafaah, 2019).

Tiga tahun terakhir ini lulusan dari jurusan Ilmu Sosial, Hukum, dan Humaniora di UT sampai dengan tahun 2019 kurang lebih sebanyak 1,803 lulusan. Banyaknya lulusan FHISIP-UT mengindikasikan bahwa FHISIP-UT dipercaya oleh masyarakat dan pemerintah sebagai perguruan tinggi yang dapat meningkatkan kualitas SDM. Namun kenyataannya, masih ada masyarakat yang mempertanyakan eksistensi lulusan FHISIP-UT dari segi kualitas. Hal tersebut bukanlah hal baru karena sejak FHISIP- UT berdiri telah menuai banyak kritikan terutama yang berkaitan dengan (1) kualitas lulusan FHISIP-UT yang dipandang lebih rendah dari lulusan PT lain, (2) kualitas pembelajaran yang menerapkan belajar mandiri sehingga mahasiswa FHISIP-UT disebut mahasiswa teori, (3) bagaimana sistem pelayanan menangani pembelajaran bagi mahasiswa yang jumlahnya puluhan ribu, dan (4) kualitas ujian yang pelaksanaannya massal. FHISIP-UT sangat menyadari kelemahan dalam pelaksanaan pendidikan jarak jauh, namun FHISIP-UT terus mencari dan melakukan penelitian dalam rangka peningkatan mutu FHISIP-UT, diantaranya melalui tracer study yang telah dilakukan khusus untuk Program Studi IImu Hukum.

\section{METODE}

Megafury Apriandhini / Tracer Study Lulusan Program Studi Ilmu Hukum Universitas Terbuka 
Studi ini menggunakan metode campuran, yaitu kuantitatif melalui survei melalui email dan focus group discussion (FGD) di UPBJJ yang dilakukan terhadap lulusan dan pengguna lulusan Prodi Ilmu Hukum Jurusan Hukum, Sosiologi dan Humaniora (ISHH) FHISIP UT yang lulus sampai dengan tahun 2019. FGD dilakukan di empat UPBJJ yaitu UPBJJ Jakarta, UPBJJ Purwokerto, UPBJJ Bengkulu, dan UPBJJ Jayapura dengan pertimbangan lulusan dalam jumlah besar.

Populasi pada Tracer Study adalah seluruh lulusan program studi S1 IImu Hukum FHISIP-UT yang lulus sampai dengan 20 sejumlah 1.402. Sampel merangkap populasi dilakukan terhadap keseluruhan lulusan melalui email dan google form. Pengumpulan data dilakukan melalui pengisian kuesioner. Pengisian kuesioner dilakukan terhadap keseluruhan lulusan, atasan lulusan, dan teman sejawat lulusan. Kuesioner akan dikirimkan kepada target responden dengan menggunakan cara yaitu: 1) melalui email; 2) melibatkan staf UPBJJ-UT; 3) melibatkan Pokjar. Jumlah kueisioner yang dikirimkan sebanyak 1.406 buah. Kuesioner untuk atasan dan teman sejawat akan dikirimkan bersamaan dengan kuesioner lulusan, sehingga jumlah sampel responden atasan sama dengan jumlah sampel responden lulusan.

Data yang diperoleh dari kuesioner akan diolah kemudian untuk dianalilis dan diresume sebagai hasil dari pengambilan data. Dari analisis data tersebut dibuat sebuah intrumen hasil penelitian untuk meningkatkan lulusna mahasiswa Prodi IImu Hukum dan memperbaiki kualitas pelayanan dan akademik mahasiswa.

Data yang diperoleh dianalisis secara deskriptif menggunakan persentase dan disajikan dalam berbagai bentuk grafik/diagram. Hal ini dilakukan untuk mempermudah dalam pembacaan hasil analisis.

Pengembangan instrumen penelitian Tracer Study dilakukan melalui beberapa tahapan, yaitu:

a. Penyusunan instrumen penelitian.

b. Analisis instrumen hasil uji coba.

c. Revisi instrumen berdasarkan hasil analisis dan verifikasi.andaan.

Instrumen dibagi menjadi 9 bagian yang secara garis besar membahas hal-hal sebagai berikut.

a. Profil lulusan .

b. Pengalaman Belajar di UT.

c. Posisi dan peran lulusan dalam lapangan kerja dan masyarakat.

d. Kualitas kinerja lulusan pada tugas dan jabatannya.

e. Daya saing lulusan dalam lapangan kerja dan studi lanjut.

f. Kompetensi lulusan.

g. Kepuasan lulusan terhadap ilmu yang diperolehnya dibandingkan dengan kebutuhan dalam pekerjaannya.

h. Pengalaman dan harapan studi lanjut.

i. Komunikasi antar alumni dan antara alumni dengan institusi.

\section{HASIL PENELITIAN DAN PEMBAHASAN}

\section{Profil Alumni Prodi IImu Hukum FHISIP UT}

Berdasarkan hasil survey alumni atau studi penelusuran telah diperoleh kondisi dari alumni sebagai berikut:

a. Target alumni adalah mereka yang lulus pada tahun 2017-2019

b. Jumlah Alumni sebanyak 1402

Megafury Apriandhini, et. al. / Tracer Study Lulusan Program Studi IImu Hukum Universitas Terbuka 
c. Dari 1402 orang yang mengisi hasil studi penelusuran hanya sebanyak 353 alumni atau sekitar $25.17 \%$

Tabel 1

Jumlah Responden yang mengisis Tracer Study Berdasarkan Angkatan

\begin{tabular}{|c|c|c|c|}
\hline No & Angkatan & $\begin{array}{c}\text { Jumlah } \\
\text { Responden }\end{array}$ & Prosentase \\
\hline 1 & 2012 & 1 & $0,2 \%$ \\
\hline 2 & 2013 & 87 & $24,64 \%$ \\
\hline 3 & 2014 & 131 & $37,11 \%$ \\
\hline 4 & 2015 & 102 & $28,89 \%$ \\
\hline 5 & 2016 & 28 & $7,93 \%$ \\
\hline 6 & 2017 & 4 & $1,13 \%$ \\
\hline Tota & & & $100 \%$ \\
\hline
\end{tabular}

d. Indeks Prestasi Kumulatif rata-rata alumni adalah 3,10.

e. Lama studi rata-rata alumni adalah 3 tahun 6 bulan.

f. Pekerjaan terbanyak yang ditekuni oleh Sebagian besar lulusan adalah sebagai Aparatur Sipil Negara (ASN), disusul pada urutan kedua profesi yang ditekuni adalah sebagai Polisi, Pengacara, Pegawai swasta.

g. Jumlah lulusan yang sudah bekerja saat pengisian kuesioner sebanyak $95 \%$ atau 337 responden, dimana sebanyak $94 \%$ atau 320 responden telah memiliki pekerjaan sebelum lulus dari Program Studi IImu Hukum atau mereka telah bekerja saat masih berstatus mahasiswa. Sisanya sebanyak 17 responden atau 6\% baru memperoleh pekerjaan setelah lulus kuliah dari Program Studi IImu Hukum Universitas Terbuka. Dan sebanyak 16 responden pada saat penelusuran ini masih berstatus pencari kerja/belum bekerja.

h. Lama masa tunggu pencarian kerja Sebagian besar alumni yang memulai bekerja setelah lulus memiliki waktu tunggu selama kurang dari dua bulan setelah lulus.

2. Studi Penelusuran terhadap Penilaian Alumni terkait Kepuasan atas Mutu Pelayanan Penyelengaraan Pendidikan pada Program Studi IImu Hukum FHISIP Universitas Terbuka

Penilaian kepuasaan mutu pelayanan penyelenggaraan Pendidikan pada Program Studi IImu Hukum FHISIP UT dapat ditinjau dari beberapa aspek :

a. Aspek pembelajaran

b. Aspek materi pembelajaran

c. Aspek Layanan bantuan belajar

Pada aspek pembelajaran yang meliputi interaksi antara mahasiswa dan dosen atau tutor, Sebagian besar menilai metode pengajaran atau pembelajaran sudah bagus hal ini dilihat dari $90 \%$ responden merasakan kepuasan dalam aspek pembelajaran. Untuk saran perbaikan diharapkan agar dosen/tuton untuk lebih aktif lagi dalam menilai tugas dan diskusi mingguan (Akrom, 2019).

Sementara untuk aspek materi pembelajaran Sebagian besar responden juga memberikan nilai positif atas materi-materi baik itu yang berasal dari Buku Materi 
Pokok (BMP), materi inisiasi, diskusi dan tugas setiap minggunya.Mereka berharap agar diskusi lebih banyak lagi diberikan untuk mengasah kemampuan dari mahasiswa.

Pada aspek layanan bantuan belajar responden mengharapkan untuk lebih banyak diadakan layanan bantuan belajar secara tatap muka pada UPBJJ. Dan kedepannya responden mengharapkan untuk segera dibukanya program pascasarjana atau S2 di bidang IImu Hukum.

\section{Penilaian Alumni terhadap Kesesuaian Pekerjaan yang Diperoleh dengan Kompetensi Profil Lulusan Progran Studi Ilmu Hukum FHISIP Universitas Terbuka}

Berdasarkan hasil tracer studi diperoleh gambaran kesesuaian antara pekerjaan yang diperoleh para lulusan dengan kompetensi profil lulusan yang ada pada Program Studi IImu Hukukm FHISIP UT. Aspek yang dilihat dari Aparatur Pemerintah maupun non Pemerintah di Bidang Hukum, Konsultan atau Penasihat Hukum, Perancang kontrak dan perjanjian.

Pada aspek aparatur pemerintah maupun non pemerintah di bidang hukum sebagai tenaga professional yang mengkaji dan menganalisis masalah hukum serta merancang dokumen hukum bisa dilihat dari lulusan yang bekerja sebagai ASN maupun yang bekerja di perusahaan swasta yang memiliki jobdesk merancang dokumen perjanjian, Adapula aspek konsultan di bidang hukum yang berprofesi sebagai pengacara. Serta Penegak hukum yang berprofesi sebagai Polisi.

Dari penelusuran terhadap pengguna Alumni diperoleh hasil bahwa lulusan dari program studi ilmu hukum UT memiliki daya kompetitif dengan lulusan dari institusi lain. Kemampuan mereka pun bisa dibilang bagus dan memiliki etos kerja serta semangat yang tinggi dalam bekerja.

\section{KESIMPULAN}

Berdasarkan hasil penelitian dan pembahasan pada penjelasan sebelumnya, dapat diperoleh kesimpulan sebagai berikut : (1.) Sebagian besar alumni telah memiliki pekerjaan sebelum mereka lulus atau dengan kata lain mereka telah bekerja saat masih berstatus mahasiswa pada Program Studi IImu Hukum FHISIP UT. (2.) Penilaian alumni terhadap pelayanan mutu Pendidikan pada Program Studi IImu Hukum FHISIP UT, Sebagian besar alumni memberikan penilaian yang baik serta memuaskan atas pelayanan mutu Pendidikan baik ditinjau dari aspek pembelajaran, materi pembelajaran serta layanan bantuan belajar.

Saran bagi perbaikan institusi khususnya bagi Program Studi IImu Hukum FHISIP UT adalah dengan memberikan peningkatan pelayanan mutu Pendidikan yang lebih baik lagi serta diharapkan untuk segera membuka program pascsarjana (S2) di bidang Ilmu Hukum.

\section{REFERENSI}

Akrom, Akrom. (2019). Survei Layanan Akademik Mahasiswa Jurusan Pendidikan Guru Madrasah Ibtidaiyah. Primary: Jurnal Keilmuan Dan Kependidikan Dasar, 10(2), 159_ 176.

Atmini, Siti, Budianto, Alexius Endy, \& Ahsan, Moh. (2019). Analisis dan Pengembangan Sistem Informasi Tracer Study Menggunakan Metode Waterfall Berbasis Web. Semnas SENASTEK Unikama 2019, 2.

Megafury Apriandhini, et. al. / Tracer Study Lulusan Program Studi Ilmu Hukum Universitas Terbuka 
Bakti, Very Kurnia, Noval, Mohammad, \& Aji, Eko Purnomo Bayu. (2017). Sistem Pre Kompilasi Data Tracer Studi Online Ditjen Belmawa Ristekdikti (Studi Kasus: Politeknik Harapan Bersama). Jurnal Informatika: Jurnal Pengembangan IT, 2(1), 50-53.

Baro'ah, Siti. (2020). Kebijakan Merdeka Belajar sebagai Strategi Peningkatan Mutu Pendidikan. Jurnal Tawadhu, 4(1), 1063-1073.

bin Saper, Md Noor, Mahalle, Salwa, Nurrahmi, Hesty, Elmansyah, M. S. I., Heriyanti, M. Pd, Irfany, Amalia, Sakdiah, Halimatus, Fauzi, Ali, Wulansari, Putri, \& Sari, Eka Puspita. (2018). Proceedings International Conference on Guidance and Counseling 2017 (ICGC" 17): Multicultural Guidance \& Counseling (Vol. 1). Elmans' Institute bekerjasama dengn Jurusan Bki Fuad lain Pontianak.

Fuadi, Djalal. (2016). Internasionalisasi Perguruan Tinggi; Studi Multisitus Pada Perguruan Tinggi Islam di Yogyakarta.

Nurdyansyah, Nurdyansyah, \& Andiek, Widodo. (2017). Manajemen Sekolah Berbasis ICT. Universitas Muhammadiyah Sidoarjo.

Rini, Yuli Sectio, \& Tari, Jurusan Pendidikan Seni. (2013). Pendidikan: Hakekat, Tujuan, dan Proses. Jogyakarta: Pendidikan Dan Seni Universitas Negeri Jogyakarta.

Syafaah, Aah. (2019). Tracer Study Kompetisi Alumni Jurusan Sejarah Kebudayaan Islam (Ski) Di Era Revolusi Industri 4.0: Peluang Dan Tantangan. Lp2m, Institut Agama Islam Negeri (IAIN) Syekh Nurjati Cirebon.

Yahya, Luqman Andi. (2018). Respon stakeholder terhadap lulusan Pendidikan Kimia Fakultas Sains dan Teknologi UIN Walisongo Semarang. UIN Walisongo Semarang.

(C) 2020 by the authors. Submitted for possible open access publication under the terms and conditions of the Creative Commons Attribution (CC BY SA) license (https://creativecommons.org/licenses/by-sa/4.0/) 